\title{
Über Kohlehydratverbrennung.
}

II. Mitteilung.

Die aktivierende Substanz des Pankreas.

Von

Otto Cohnheim.

Mit zwei Abbildungen.

(Aus dem physiologischen Institut Heidelberg.)

(Der Redaktion zugegangen am 10. Juli 1904.)

Im Sommer 1903 habe ich Versuche mitgeteilt, ${ }^{1}$ ) nach denen die Muskeln von Hunden und Katzen ein glykolytisches Ferment enthalten, das aber an sich unwirksam ist und der Aktivierung durch Pankreas bedarf.

Es kam nun zunächst darauf an, diese Fermente zu isolieren, da nur dann eine weitere Untersuchung Erfolg versprach. Für den wirksamen Bestandteil des Pankreas ist mir das einigermaßen gelungen. Er ist kochbeständig, löst sich in Wasser, in 96\% igem Äthylalkohol, dagegen nicht in Äther, und läßt sich auf Grund dieser Eigenschaften leicht von den Eiweißkörpern, Fermenten und überhaupt den meisten Bestandteilen des Pankreas trennen.

Der Muskelsaft wurde wie früher gewonnen, indem die Muskeln von entbluteten Katzen gefroren, mit der Kosselschen Schneidemaschine zerkleinert und nach Zusatz von Kieselguhr mit der Buchnerpresse ausgepreßt wurden. Zu den Versuchen dienten stets je $40 \mathrm{ccm}$ des mit Traubenzucker versetzten Muskelsaftes (entsprechend etwa $75 \mathrm{~g}$ Muskeln). Dazu kamen

1) O. Cohnheim, Diese Zeitschrift, Bd. XXXIX, S. 336 (1903). Zuerst vorgetragen im Heidelberger Medizinischen Verein am 28. Juli 1903 (Referat Münchener Medizinische Wochenschrift, 1903, S. 2029). Ich gebe das Datum ausdrücklich, da im Zentralblatt für Physiologie die Priorität für die im August 1903 erschienene Dissertation von Fräulein R. Hirsch reklamiert wird. 
$5 \mathrm{ccm}$ einer gesättigten Lösung von Natriumbikarbonat, reichlich Toluol und wechselnde Mengen der Pankreasextrakte. Dann wurden die Flaschen 16-20 Stunden in den Brutschrank gestellt. Die Zuckerbestimmung erfolgte nach Pavy, nachdem das Eiweiß durch Kochen mit Kochsalz und Essigsäure entfernt war.

\section{Versuch 1.}

Ein Katzenpankreas von $8 \mathrm{~g}$ wird mit Sand zerrieben und wiederholt mit Alkohol von 96\% extrahiert, die alkoholische Lösung bei $40^{\circ}$ verdampft, der Rückstand mit $80 \mathrm{ccm}$ Wasser aufgenommen.

Kein Zusatz: $\quad 26 \mathrm{mg}$ Dextrose verschwunden

$10 \mathrm{ccm}$ Pankreasextrakt: 62 ,

\section{Versuch 2.}

Geradeso. Katzen- und Rindspankreas.

\section{Kein Zusatz:}

Kein Zucker verbrannt

$4 \mathrm{ccm}$ Katzenpankreas: $50 \mathrm{mg}$,

8 . Rindspankreas: $65, \infty$

\section{Versuch 3.}

$30 \mathrm{~g}$ Rindspankreas werden mit Alkohol extrahiert, die alkoholische Lösung bei $40^{\circ}$ zur Trockene eingedampft und der Rückstand erst mit Äther, dann mit Alkohol, dann mit Wasser extrahiert. Die 3 Extrakte werden wieder eingetrocknet und in je $300 \mathrm{ccm}$ Wasser gelöst. Zum Versuch dienen je $8 \mathrm{ccm}$ der wässerigen Lösungen.

Ätherlöslich : $4 \mathrm{mg}$ Dextrose verschwunden

In Äther unlöslich, in Alkohol löslich:

Rückstand von der Alkoholextraktion:

$77 \div ;$

\section{Versuch 4.}

Wie im vorigen Versuch, nur werden die Lösungen zum Teil gekocht.

Kein Zusatz:

In Äther unlöslich, in Alkohol löslich, ungekocht; $8 \mathrm{ccm}$ :

Die fertige Lösung aufgekocht; $8 \mathrm{ccm}$ :

Pankreas kochend extrahiert, dann geradeso behandelt; $8 \mathrm{ccm}$ :

Ebenso behandelt; $6 \mathrm{ccm}$ :
$47 \mathrm{mg}$ Dextrose verschwunden

83 »
85 »
$80 \gg$
$92 \gg$




\section{Versuch 5 .}

Kein Zusatz:

$34 \mathrm{mg}$ Dextrose verschwunden

Katzenpankreas, Alkoholextrakt: 100 ,

Doch bleibt bei der Extraktion des frischen, ungekochten Pankreas mit Alkohol ein gewisser Anteil der wirksamen Sub$\operatorname{stanz}$ an den Eiweißkörpern haften.

\section{Versuch 6 .}

1 Katzenpankreas wird 3mal mit Alkohol, dann mit Äther extrahiert, der Rückstand in Wasser aufgeschwemmt, sodaß $10 \mathrm{ccm}$ auf $1 \mathrm{~g}$ Pankreas kommen.

Kein Zusatz: $\quad 34 \mathrm{mg}$ Dextrose verschwunden

20 ccm Pankreas: 174 , ,

\section{Versuch 7.}

Genau so.

Kein Zusatz: $\quad 35 \mathrm{mg}$ Dextrose verschwunden $10 \mathrm{ccm}$ Extrakt: 91 , ,

Es erwies sich daher als zweckmäßiger, das Pankreas erst mit siedendem Wasser auszukochen und erst den Rückstand des weggedampften Wassers mit Alkohol zu extrahieren. Ich habe schließlich folgende Methode angew idet: Rindspankreas wird zerhackt, in siedendes Wasser geworfen und zur Trockene eingeengt. Der Rückstand wird mit mehreren Portionen Alkohol extrahiert, die alkoholische Lösung eingedampft und der Rückstand mit Äther ausgekocht. Der in Äther unlösliche Rückstand wird entweder direkt in Alkohol gelöst oder nochmals in Wasser gelöst, filtriert, eingedampft und nun erst mit Alkohol aufgenommen. Man bekommt so eine gelblich gefärbte, alkoholische Lösung, die den wirksamen Bestandteil des Pankreas enthält. $\mathrm{Zu}$ den Versuchen habe ich eine bestimmte Menge dieser Lösung genommen, den Alkohol weggedampft und den Rückstand in soviel Wasser gelöst, daß $10 \mathrm{ccm}$ auf $1 \mathrm{~g}$ Pankreas kamen. ${ }^{1}$ )

1) Mit Rücksicht auf die zu erwartende therapeutische Verwendung haben auf meine Veranlassung die Vereinigten Chemischen Werke Charlottenburg die Darstellung eines kochbeständigen, alkohollöslichen Aktivators aus dem Pankreas zum Patent angemeldet. 
Ich führe einige Versuche mit einer solchen Lösung an:

8. $40 \mathrm{ccm}$ Muskelsaft $+8 \mathrm{ccm}$ Extrakt: $107 \mathrm{mg}$ Dextrose verbrannt

9. Kein Zusatz:

$8 \mathrm{ccm}$ Extrakt:

10. Rindfleisch. Kein Zusatz:

$6 \mathrm{ccm}$ Extrakt:

11. Katzenfleisch. Kein Zusatz:

5 ccm Extrakt:

\begin{tabular}{|c|c|c|}
\hline 27 & & $D$ \\
\hline 56 & 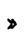 & $\gg$ \\
\hline 44 & ק & $\gg$ \\
\hline 76 & 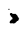 & 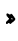 \\
\hline 128 & 》 & , \\
\hline 187 & , & D \\
\hline
\end{tabular}

Der Grund für die großen quantitativen Unterschiede wird weiter unten auseinandergesetzt werden.

Die Löslichkeitsverhältnisse des Pankreasaktivators, seine Kochbeständigkeit und seine Alkohollöslichkeit zeigen, daß er kein Ferment ist, sie stellen ihn vielmehr auf eine Stufe mit den andern länger bekannten Produkten der inneren Sekretion, dem Adrenalin, dem Jodothyrin und dem Sekretin. Vor allem aber besteht eine vollkommene Übereinstimmung mit dem Körper, den Magnus ${ }^{1}$ ) in der Leber entdeckt hat: Magnus fand, daß sich das esterspaltende Ferment der Leber in $2 \mathrm{Be}-$ standteile zerlegen läßt, deren einer kochbeständig, in Wasser und Alkohol löslich, in Äther unlöslich ist. Auch daran ist zu erinnern, daß Ehrlichs Amboceptoren zwar nicht kochbeständig sind, aber doch weit höhere Wärmegrade vertragen, als die empfindlicheren Komplemente und die meisten Fermente.

Was nun die Wirkungsart dieses Körpers anlangt, so ergab sich ein überraschender Befund:

Setzt man nämlich $z u$ einer gleichbleibenden Menge von Muskelsaft und von Zucker steigende Mengen Pankreas hinzu, so nimmt die Wirkung erst zu und dann wieder ab. Es gilt das sowohl, wenn man das ganze Pankreas verwendet, als auch für das alkoholische Extrakt des gekochten und des ungekochten Pankreas, als auch für den bei der Alkoholextraktion an den Eiweißkörpern haftenden Aktivator. Ich gebe einige Beispiele:

1) R. Magnus, Diese Zeitschrift, Bd. XLII, S. 149, 1904. 


\section{Versuch 12.}

Pankreas mit Quarz zerrieben und mit 10 facher Menge Wasser extrahiert:

Kein Zusatz: $\quad 50 \mathrm{mg}$ Dextrose verbrannt

$10 \mathrm{ccm}$ Pankreas: 100 , ,

20 , > 127 , >

50 > 77 > >

Versuch 13.

Pankreas mit Alkohol und Äther extrahiert. Rückstand in der 10 fachen Menge Wasser aufgeschwemmt.

Kein Zusatz

5 ccm Pankreas

10 ,

$20 \gg$,
$35 \mathrm{mg}$ Dextrose verschwunden

76 ,

$91 \gg$,

$25, \times$,

Versuch 14.

Geradeso.

Kein Zusatz
$10 \mathrm{ccm}$ Pankreas
$15:$
20 :
88 :

$34 \mathrm{mg}$ Dextrose verschwunden

115

150

174

93 ,

0 »

Versuch 15.

Pankreas mit Alkohol extrahiert, Alkohol bei $40^{\circ}$ abgedampft und der Rückstand in $10 \mathrm{ccm}$ Wasser pro $1 \mathrm{~g}$ Pankreas aufgenommen.

Kein Zusatz

$10 \mathrm{ccm}$ Pankreas

$20>$.

$30 \gg$ \$

$50 \gg$ >
$26 \mathrm{mg}$ Dextrose verschwunden

62 ,

0 >

$0 \gg$

$0 \gg$ >

Versuch 16.

Pankreas kochend extrahiert. Alkoholische Lösung.

Kein Zusatz

$6 \mathrm{ccm}$ Pankreas

10 »
$47 \mathrm{mg}$ Dextrose verschwunden

92

48 . 


\section{Versuch 17.}

Lösung, wie oben auseinandergesetzt.

\begin{tabular}{|c|c|c|}
\hline \multicolumn{3}{|c|}{$\begin{array}{l}\text { Kein Zusatz } \\
5 \mathrm{ccm} \text { Lösung }\end{array}$} \\
\hline 8 & $\triangleright$ & $\gg$ \\
\hline 11 & $\triangleright$ & $\triangleright$ \\
\hline 16 & $\triangleright$ & $\triangleright$ \\
\hline & $\gg$ & » \\
\hline
\end{tabular}

$10 \mathrm{mg}$ Dextrose verschwunden

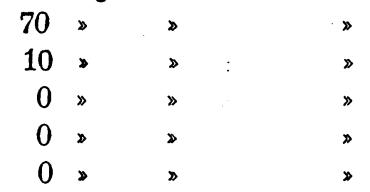

Versuch 18.

Kein Zusatz
5 Pankreas
6
7
8
9

$\begin{array}{lll}128 & \text { mg Dextrose verschwunden } \\ 187 & \searrow & \text { \} } \\{79} &{\searrow} &{\searrow} \\{56(?)} &{\searrow} &{\searrow} \\{68(?)} &{\searrow} &{\searrow}\end{array}$

Man findet also ein Maximum der glykolytischen Wirkung, wenn man $75 \mathrm{~g}$ Muskeln mit etwa $0,8 \mathrm{~g}$ Pankreas oder etwas weniger kombiniert. Darüber hinaus sinkt die Wirkung. $2 \mathrm{~g}$ Pankreas hebt die Wirkung bereits ganz auf. Dieser Umstand hat mich monatelang genarrt; er ist die Ursache, daß die 2. Mitteilung sich so lange verzögert hat.

Es fragt sich, wie man sich diese eigentümliche Erscheinung erklären soll. Man könnte im Pankreas zwei Körper annehmen, einen fördernden und einen hemmenden. Dagegen spricht, daß ich die Hemmung durch Mehrzusatz in ganz der gleichen Weise erhielt, als ich das ganze Pankreas, den gekochten und den ungekochten Alkoholextrakt oder die Alkoholfällung verwendete. Die beiden Körper hätten also ganz gleiche Löslichkeitsverhältnisse, und trotzdem würde immer erst der eine, dann der andere wirken. Dagegen bietet sich ein gutes Analogon in dem, was Ehrlich Komplementablenkung nennt. Neissér und Wechsberg ${ }^{1}$ ) haben gefunden, daß bei der Abtötung von Bakterien durch baktericide Sera, zu der ja ein

1) M. Neisser u. F. Wechsberg, Münchener Medizin. Wochenschrift, 1901, Nr. 18. 
Zusammenwirken von Amboceptor und Komplement erforderlich ist, ein Mehrzusatz von Amboceptor die Wirkung hemmt, unter Umständen ganz aufhebt. Sie veranschaulichen die Erscheinung durch das folgende schematische Bild:

I

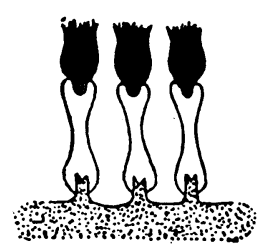

II

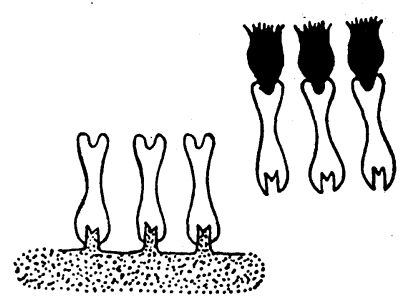

Bei I würden Bakterien, Komplement und Amboceptor gerade in richtigem Verhältnisse stehn, bei II dagegen würde ein Überschuß des Amboceptors es bewirken können, daß die Abtötung der Bakterien ausbleibt. Ob hier wirklich eine volle Analogie zu dieser Komplementablenkung vorliegt, oder ob die Hemmung durch Überschuß hier andere Gründe hat, wird sich erst entscheiden lassen, wenn die Beziehungen zwischen Zucker, Aktivator und glykolytischem Ferment durchsichtiger geworden sind.

Dagegen läßt sich sofort etwas anderes aufklären. Ich habe in der 1. Mitteilung beschrieben, daß Blutserum die Reaktion stört, andererseits habe ich inzwischen eine Reihe von Fällen beobachtet, bei denen die Entblutung der Katzen unvollständig war, und bei denen das bluthaltige Muskelfleisch bereits ohneZusatz von Pankreas eine nicht unbeträchtliche glykolytische Wirkung entfaltete (Versuch 1, 4-7, 9-16, 18). Insbesondere konnte ich dies ganz regelmäßig an Rindfleisch beobachten, das ich frisch vom Schlachthaus bezog und das natürlich immer Blut enthält. $40 \mathrm{ccm}$ Muskelsaft ließen bis zu $150 \mathrm{mg}$ Dextrose, sogar noch mehr verschwinden. Ja, in einigen Fällen sah ich, daß Pankreaszusatz die Glykolyse nicht begünstigte, sondern die bestehende hemmte. 
Versuch 19.

Rindfleisch. Pankreaslösung.

$\begin{array}{lrl}\text { Kein Zusatz } & 116 \mathrm{mg} \text { Dextrose verschwunden } \\ 5 \text { Plerosin } & 81 \\ 8 \text { Die Auflösung gab: } & 66\end{array}$

\section{Versuch 20.}

Katzenfleisch. Katzenserum. Gekochter Alkoholextrakt von Rindspankreas.

\begin{tabular}{|c|c|c|c|c|c|}
\hline \multirow{3}{*}{\multicolumn{2}{|c|}{$\begin{array}{c}\text { Kein Zusatz } \\
8 \mathrm{ccm} \text { Pankreasextrakt }\end{array}$}} & & \multicolumn{3}{|c|}{$0 \mathrm{mg}$ Dextrose verschwunden } \\
\hline & & & 107 & $\triangleright \quad$ & \\
\hline & & $+7 \mathrm{ccm}$ Serum & 75 & $\triangleright$ & $\triangleright$ \\
\hline & Serum & & 50 & » & $\bowtie$ \\
\hline & Pankreasextrakt & $t+3 \mathrm{ccm}$ Serum & 100 & . & $\triangleright$ \\
\hline
\end{tabular}

Das Blutserum enthält also selbst Aktivator, und bluthaltige Muskeln zeigen daher ohne weiteren Zusatz Glykolyse. Setzt man zu derartigen Muskeln Pankreas, so tritt eine Hemmung durch Mehrzusatz ein, während sich wenig Serum und wenig Pankreas zu guter Wirkung summieren. So hat mich die Überschußhemmung zur irrtümlichen Annahme eines Antiferments geführt.

Ich hoffe, bald über die Isolierung des glykolytischen Ferments der Muskeln, über die Spaltungsprodukte und über Tierversuche berichten zu können. Dann werde ich auf die Literatur genau eingehen können. Heute nur eine kurze Bemerkung. Da ich jetzt gefunden habe, daß bluthaltiges Fleisch auch ohne Pankreaszusatz Glykolyse zeigt, so könnte Stoklasa ${ }^{1}$ ) das als eine Bestätigung seiner Angaben auffassen. Das ist deshalb nicht der Fall, weil bei der Muskelglykolyse keine irgend erhebliche Produktion von Kohlensäure zu beobachten ist. Da Stoklasa immer die berechnete Menge Kohlensäure findet, so muß er Bakterienwirkung gesehen haben und keine fermentative Glykolyse. Auch ist das Muskelferment außerordentlich empfindlich gegen saure Reaktion, ein weiterer Be-

1) J. Stoklasa, Centralbl. f. Physiol., 1903, Nr. 17. Daselbst sind seine und seiner Schüler Arbeiten zitiert. 
weis, daß Stoklasa nur Bakterien in Händen gehabt hat. Ein Zusatz von 1-2\% Toluol genügt in einer eiweißfreien Lösung. Ich habe mich aber wiederholt davon überzeugt, daß der eiweißhaltige Muskelsaft trotz 2\% Toluol am nächsten Tage von Bakterien geradezu wimmelt. Battelli ${ }^{1}$ ) und $\mathrm{Hirsch}^{2}$ ) haben dasselbe beobachtet. - Daß meine Versuche nicht durch Bakterien vorgetäuscht wurden, ergibt sich mit Sicherheit aus der beschriebenen Hemmung durch Mehrzusatz.

1) F. Battelli, C. r. 14. Dez. 1903.

2) R. Hirsch, Hofmeisters Beitr., Bd. \&, S. 535, 1903. 